\title{
Systemic Metaphors and Integrative Biology
}

\begin{abstract}
The purpose of this paper is to provide a conceptual framework for examining and integrating systemic thinking in biology through the analysis of a number of systemic metaphors. After a brief examination of the roles that systemic metaphors can play in model development, a general framework is presented for integrating a range of key constructs such as hierarchy and organisation as well as the scope for use of the ecosystem metaphor. The idea of an ecology of biological information is used to encapsulate general thinking about networks, hierarchies and nestings at various scales and times and this leads on to the role played by the cognitive system metaphor. After a discussion of a number of occurrences of the cognitive metaphor a complementary systemic metaphor - verb-glue-text - is discussed. The paper concludes with a brief look at some of the conceptual constraints related to this metaphor. In order to make the paper integrative a broad range of biological examples are discussed from molecules to ecosystems.
\end{abstract}

\section{Introduction}

This paper will provide a conceptual framework for examining and integrating systemic thinking in biology through the analysis of a number of systemic metaphors (Paton, 1992). Biological knowledge is both diverse and rapidly expanding. It encompasses a range of temporal and spatial scales - from picoseconds to millions of years and from nanometres to tens of metres. The tools of thought and foci of attention can differ across these scales whilst at the same time there are some ideas and themes which provide an integrative effect. One example of the latter is the application of systemic ideas. The value of using such ideas will be demonstrated by looking at ways they can be used to integrate existing knowledge and also a way of anticipating future hypotheses. 
Clearly, much has already been written about systems and biology and the important areas of General Systems Theory and Cybernetics (e.g., Bertalanffy, 1973), Anticipatory Systems (Rosen, 1985) and Autopoietic Systems (e.g., Varela, 1979) will not be explored in any depth here. The present examination of systemic metaphors should be understood in relation to the conceptual complexity and sometimes muddled features of biological knowledge. This lack of conceptual clarity is not restricted to biology. For example, Roche (1990) demonstrated the need for a more coherent theoretical and conceptual framework for classical physics producing a detailed list of ideas and concepts where their nature and status should be explored more fully.

\section{Systems, Metaphors and Models}

Many biological concepts are polytypic and multidimensional in nature. There are multiple levels of organisation in which ideas and tools of thought used at one level can be displaced to other levels. Individuality and heterogeneity apply to all spatial scales, as do issues of complexity and openness. In practice many extant biology-specific concepts are nonreducible to the concepts and theories of the physical sciences. Many biological theories are much more than ordered collections of statements. They also contain an iconic component. We identify such theories as providing the representational framework for dealing with both observable and non-observable entities which Harre (1986) called Type 2 Theories. The role that metaphor plays in theory development and articulation is summarised by Harre when he notes that at the core of human cognitive processes are:

webs of meaning held together by ordered sequences of analogies in which metaphor and simile are the characteristic tropes of scientific thought...

Harre (1986) p7

This reflects the position followed in the present paper building from a number of realist philosophers of science and also psychologists who place an emphasis on the role of theoretical structures such as Carey, Keil and Medin. A theory is the evolving cognitive complex. Theoretical knowledge and thought provides the conceptual environment in which models can be constructed, predictions and explanations made and hypotheses generated.

Metaphors and models are very closely linked together. Models based on a source (or sources) which differ from the subject require the articulation of one thing in terms of something else. The language of such models is metaphorical and metaphor provides the linguistic context in which models are described and analogies and similes are made (e.g., Harre, 1986). Three important roles played by systemic metaphors in biological domains are: 
- catechretic - they can supply new terms to the theoretical vocabulary

- ontological - they are involved in the formulation of hypothetical entities

- didactic - they facilitate dialogue between a teacher and a student The systemic metaphors discussed here share three key properties:

- interactions among parts

- organisational form or structure resulting from the interactions

- whole-system functionality or the emergence of behaviours of the whole that are greater than the summing together of the parts

Systemic metaphors can be utilised in Type 2 theoretical frameworks. For example, a biological 'cell' (the term itself is a visual metaphor) or its parts have variously been described as machine, network, computer, factory, laboratory, society, ecosystem and text (see also Paton, 1993a). They act as sources for novel biosystems metaphors. Because they are recognised as being based on Type 2 theories we can anticipate not only the predictive capacity of resulting models (e.g., when formulated within some mathematical framework) but also the explanatory power generated by the underlying statement-picture complex of observable and unobservable entities.

\section{An Examination of some Systemic Metaphors}

This section begins with a brief look at some key intellectual constructs related to systemic thinking such as hierarchy, network and level of organisation. One example from neuronal systems is introduced to illustrate the sophistication in thinking needed to mobilise our thinking in these domains. The ideas are then considered in relation to systemic metaphors in general followed by some specific cases related to ecology and biological information.

Consider the case of a circuit of neurones. The organisation of this system is not straightforward, although its definition as a system could follow a traditional view as outlined for example in the following nineteenth century description:

A system is a complexity from the anatomical point of view, it is a functional unit from the physiological point of view.

Rubin, 1878 cited in Schiller (1968)

However, current thinking is far from simple and even the notion of "functional unit" with its attendant machine-dominated stance is problematic. Neuronal circuits are organised at many scales of size and time. Even at the microphysical level, there is a wide discussion on how quantum processes may play a part especially in regions of a neurone where there are large macromolecular protein complexes such as microtubules and the pre-synaptic vesicular grid. 
This level interacts with the mesoscopic scale in a vertical flow of information between scales (Conrad, 1990, Arhem, 1996). Neuronal systems are also multimodal with regard to the types of signal they process. There are many levels of interactions. Neurones not only generate information through action potentials, it is also produced and relayed via electrotonic effects, localised phenomena and chemical mediators. For example, Marder (1998) reviews how both the firing frequencies of neurones in a circuit and the modulatory environment provided by a number of chemical species contribute to the intrinsic and synaptic properties that produce behaviour. Indeed, the notion of a unit of computation in a neuronal system is somewhat problematic in that information processing is taking place at multiple levels, such as synapses, dendritic spines, microcircuits, dendritic trees and local circuits (e.g., Shepherd, 1990). Getting (1989) suggests at least 24 properties at cell, synaptic and network levels that contribute to the non-linear behaviour of neuronal networks. Putting these many facets together leads to a view of a biosystem where the traditional hierarchical levels of organisation break down as the flow of information moves between the hierarchical scales and (sometimes) arbitrary decompositions.

Circuits of information processing machines or devices would be a common way of talking about models even though nestings of computational units or machines access a single metaphor. Rosen (1991) provided a powerful critique of the limitations of the machine metaphor in biology especially with regard to causality and the development of his (and Rashevsky's) relational biology. Although it would not be appropriate to review the substantial contribution to the theoretical biology of systems here, it is worth noting that some of his ideas underpin certain aspects of the verb-glue-text metaphor discussed later (see also Paton, 1997). Other systemic metaphors could be appropriate such as society, ecology or text. For example, the brain and some of its component systems can be described as 'hermeneutic' (interpretative) devices (Erdi, 1996). It is important to note that in this context .'brain' rather than 'mind' is the hermeneut. In due course, some ways of displacing concepts related to these metaphors will be considered.

Figure 1 shows how some important ideas can be associated with several systemic metaphors. The metaphors appear in the boxes to the left and concepts that may be associated with each then appear to the right. With respect to the displacement of concepts, the recursive nature of this scheme can be exploited in a number of ways. For example, it is possible to displace concepts from one systemic metaphor to another as in the case of applying machine thinking to (say) an organism or text thinking to a society and so forth. This can lead to several different though related stances within a metaphorical framework for example:

- the text in the machine (an embedding)

- the machine as text (an analogy) 
- the society is like a text (a simile)

- the organism is a machine (an equivalence)

It is also possible to recognise embeddings for the same metaphor for example, machine in a machine, etc. A more complex situation can also arise when concepts are displaced between several systemic sources.

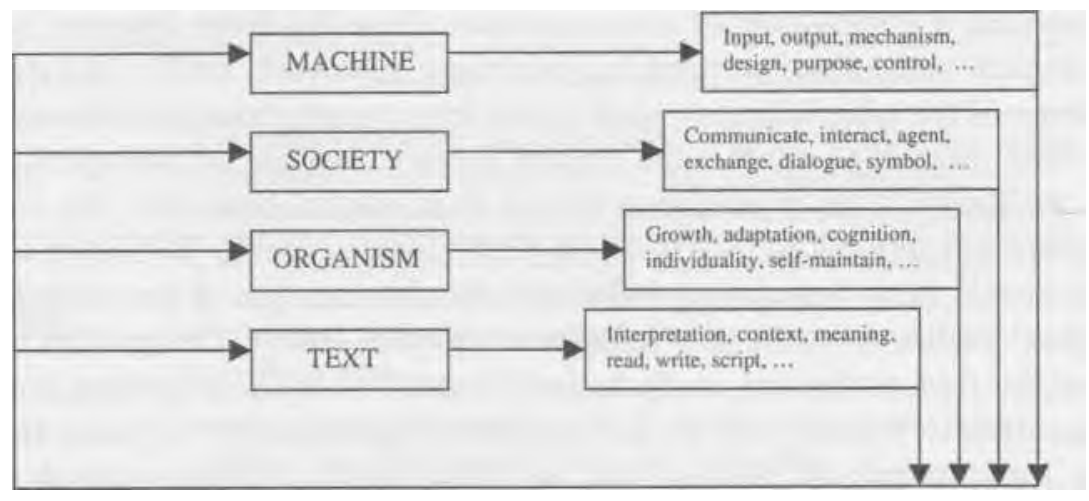

Figure 1. Recursive Relations between Systemic Metaphors

Following on from the recursive relations summarised in Figure 1, it is important to keep in mind that systemic metaphor thinking can be applied to many levels of biological organisation (Paton, 1992). In Figure 2 the many potential relations between systemic metaphors (left-hand side) and organisational levels (right-hand side) are summarised. Consider one of the many cases. It is possible to think of and model a cell as an ecosystem by displacing common ideas related to machine, society, organism and text. Such an approach provides a powerful framework for organising concepts and developing models as well as for looking at metaphorical relations at a more inclusive level of description (i.e., a metalevel). This approach has been applied to agent-based models of intracellular processes (e.g., Paton et al, 1996; Fisher et al, 1999).

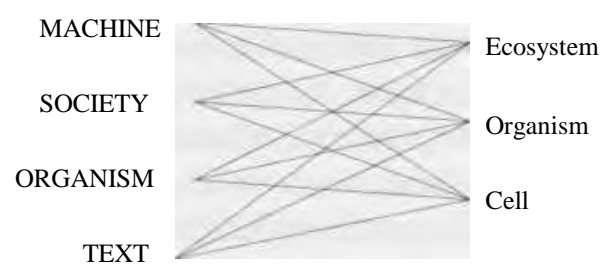

Figure 2. Displacement Relations between Systemic Metaphors and Biological Levels 
In order to focus the discussion a little more and lead on to later sections of this paper some of the metaphorical dimensions of meaning related to an ecology and an economy are now considered. Both of these terms have the same Greek root (i.e., oikos $=$ home) and share many common ideas and themes such as niche, role, competition, producer, consumer, currencies, budget and cycle as well as historical relations to global theories such as the conservation laws. Table 1 includes a comparison of some common ideas that have appeared in recent ecological and economic thinking (based on Mirowski, 1993). The right-hand column of the table indicates some of the key systemic sources influencing each of these themes. Given that the present paper is focused on biological domains we shall restrict the examination mainly to ecological concerns. The ecosystem concept was introduced by Tansley in 1935 (Tansley, 1935). To be sure a number of systemic ideas had already influenced the development of the subject such as Forbes' notion of a lake as a microcosm (Forbes, 1887). Golley (1993) reports how the first ecological study to implement Tansley's ecosystem concept in a quantitative manner was R. L. Lindeman's investigation of Cedar Bog Lake near the University of Minnesota. It led to his trophic dynamic approach in which an ecosystem is a fundamental unit (compare with 'functional units' mentioned above in the quote from Schiller).

Table 1. Some Common Themes (adapted from Mirowski, 1993)

\begin{tabular}{|l|l|l|}
\hline \multicolumn{1}{|c|}{ Ecology } & \multicolumn{1}{|c|}{ Economics } & \multicolumn{1}{c|}{ Key Systemic Source(s) } \\
\hline Historical climax community & Historicist stage theories & Text \\
\hline Cycle theories of populations & Business cycle theories & Circuit \\
\hline Material cycle/energy flow & Input/output analysis & Machine/circuit \\
\hline Evolutionarily stable strategies & Nash equilibria & Game/machine \\
\hline Artificial life & Artificial agent & Organismic/computational \\
\hline
\end{tabular}

The focus of energetic relations between trophic levels placed an emphasis on ecosystems as thermodynamic machines. Such machines also have parallels in economics for example, with regard to exchange and currency. The thermodynamic machine approach was further elaborated by for example H. T. Odum. Table 2 lists various systemic metaphors that have had an impact on ecological thinking. H. T. Odum made use of equivalent circuits from electrical systems to deal with energy flows and within this context formulated his 'maximum power principle'. It is worth noting here that there are limitations on the energy concept as applied by Odum. For example, Mansson and McGlade (1993) questioned the utility of the maximum power principle as a general principle of ecological evolution arguing that there is a fundamental problem in 
trying to describe ecosystems in a framework that has a one-dimensional energy currency. We may conclude that even at an energetic level there is a need for plurality and a number of source ideas may be appropriate in addressing certain issues.

Table 2. Some Systemic Metaphors in Ecology

\begin{tabular}{|l|l|}
\hline \multicolumn{1}{|c|}{ METAPHOR } & \multicolumn{1}{c|}{ More detailed descriptions and properties } \\
\hline MACHINE & $\begin{array}{l}\text { A number of machines can be described including chemical (i.e., matter), } \\
\text { thermodynamic (i.e., energy) or cybernetic (i.e., informational). } \\
\text { Associated terms include, balance, input, output, feedback, regulation, } \text { etc. }\end{array}$ \\
\hline ORGANISM & $\begin{array}{l}\text { A very general organismic construct would be the Gaia proposal. } \\
\text { A range of associated concepts include: open system, growth, development, } \\
\text { sickness and health, self-maintenance, autopoieisis, individuality, etc. }\end{array}$ \\
\hline SOCIETY & $\begin{array}{l}\text { Agents, context, interaction, stochastic nature, exchange, co-operate, compete, } \\
\text { hierarchy, see also TEXT and THEATRE. }\end{array}$ \\
\hline ECONOMY & $\begin{array}{l}\text { Budgets, production, consumption, etc. Also related to GAME. Displacements } \\
\text { from MACHINE related to equilibrium, feedback, input, output } \text { etc. Niche } \\
\text { ideas - roles, occupations and functions. }\end{array}$ \\
\hline THEATRE \& STAGE & $\begin{array}{l}\text { Actors, roles, setting, scenario, script, observers (audience and other actors), } \\
\text { plot, dance, etc. }\end{array}$ \\
\hline TEXT & $\begin{array}{l}\text { Ideas related to natural History, script, interpretation, meaning, context, } \\
\text { societies as texts, theme, rheme, etc. }\end{array}$ \\
\hline GAME & $\begin{array}{l}\text { Competition, co-operation, plan, exchange, win, etc. Evolutionary game } \\
\text { theories (also related to economics - see Table 1) }\end{array}$ \\
\hline
\end{tabular}

By way of contrast with Odum's circuits, Hutchinson exploited the metaphor of the ecological theatre and the evolutionary play (e.g., Hutchinson, 1965) in which the whole planet could be viewed as the ultimate theatre and the biosphere as the stage. However, the stage is complex and varied in scenery that continuously changes. Given the numbers and varieties of organisms and species on the planet, the cast is vast. The notion of position on the stage or role in the play can be related to the eco-concept of a niche where plot and action may be set in the context of reproduction and survival which in teleonomic terms results in staying on the stage. Hutchinson also placed great emphasis on the occurrence of circular causal systems (Hutchinson, 1948). In this scheme ecological relations were characterised as systems in which there were circular paths or feedback loops. Clearly, biogeochemical cycles are a good example and, because of the attendant closure principles, circular paths and causal loops reflect homoeostatic and teleonomic features. An example of ecological ideas being displaced between hierarchical levels is when Richmond (1979) uses the metaphor of a cell or 
organism as a 'habitat' for DNA to discuss the transfer of chromosomes, plasmids and transposons within bacterial populations. More generally, organismic thinking has been applied to mixed species communities to treat the whole as an organism. Taylor (1988) assessed some of the shifts and changes in the use and application of a range of metaphors among (mainly) a number of post World War 2 theoretical developments in US ecology. It is interesting to note how machine, circuit, economic, organismic and social source ideas were variously applied to ecological thinking. We now examine the application of ecological thinking to ideas about biological information.

\section{From Information to Intelligence - BioSystems and Cognition}

The previous discussion set a broad view of some roles played by systemic metaphors. This section will take up one particular idea - the notion of an ecology - and apply it to ideas about biological information. The idea of an ecology of biological information can be used to encapsulate general thinking about networks, hierarchies and nestings at various scales and times. It assists our understanding of the processes by placing an emphasis on ideas like openness, scale, multiple interaction and exchange, context, environment, competition, habitat, dialogue, evolvability and society. A number of systemic metaphors, not least circuit, organism and society, Zcan be combined. Elsewhere (e.g., Paton, 1998), it has been proposed that the organisations of hereditary information can be viewed in relation to the extant idea that life is a dance (e.g., Singer, 1959). Within the framework of this metaphor the script or score (what tends to be called the hereditary material), the cast (the metabolic agents and processes) and the stage (the cellular structure) co-exist and pre-exist the phenotypic life history which inherits them. However, in the biological context, the demarcations between script, actors and stage can change. This is partly related to the multiple functions of the interacting processes. The society metaphor has received some interesting treatments by researchers looking at interacting molecules within cellular systems (e.g., Welch, 1987; Welch \& Keleti, 1987; Marijuan, 1993; Paton, 1993a). This also leads to semiotic treatments of biological information. Thus, Emmeche and Hoffmeyer (1991) proposed that bioinformation should be articulated within the context of a 'society' metaphor as it should be understood as embracing the semantic openness that is characteristic of information exchange in human communication. Information is thus inseparable from a subject to whom the subject makes sense. This view presumes a cognitive dimension to biological information and we shall now explore this more detail.

A number of examples where a cognitive dimension to biological information can be applied shall now be explored beginning with a whole-cell example and 
then looking at networks of macromolecular interaction. Consider Albrecht- Buehler's work on cell movement and intelligence which is summarised at his website (AlbrechtBuehler, 1998). He notes:

An intelligent cell contains a compartment which is capable of collecting and integrating a variety of physically different and unforeseeable signals as the basis of problem-solving decisions

(Albrecht-Buehler, 1998)

Clearly ideas about intelligence, problem solving and decision-making imply an intelligent agent of some form. Based on experiments with fibroblasts he proposes that they have an 'eye' (the centriole). In order to make use of this 'eye' the cells generate light (infra-red radiation), detect photonic signals from various sources and integrate the information. The integration of such information requires intelligence. He further argues that if cells are intelligent, then molecules and their genes would be the 'collaborators' or even 'slaves', but not the 'masters' of the life functions of cells. Furthermore, if cells are intelligent, an organism would be the ecology of a huge population of intelligent individuals (Albrecht- Buehler, 1998). This is a very brief overview of Albrecht-Buehler's case which is defended and developed further on his website pages. It is but one case, others have made reference to cellular intelligence in for example the ways cells in multicellular organisms and protists integrate complex patterns of signals and have highly parallel distributed genomic systems.

Another example of the cognitive system metaphor relates to the often misunderstood idea of a fluid genome. Shapiro (1992) noted that McClintock, one of the first biologists to introduce this fluid viewpoint, looked at a genome as a:

complex unified system exquisitely integrated into the cell and the organism Shapiro (1992) p. 791

Her view of this complex system also made use of a cognitive dimension when she further noted:

A goal for the future would be to determine the extent of knowledge the cell has of itself and how it utilizes this knowledge in a 'thoughtful' manner when challenged from Barbara McClintock’s Nobel Prize Lecture, 1983

This outlook contrasts with theories that deal with independent genetic units, for McClintock appreciated the interconnected network relations within genomes. The importance of networks of feedback information in the processing of hereditary information is a central feature underlying the idea of 'knowledgeable' genetical systems (see e.g., Holmquist \& Filipsk, 1994; Thaler, 1994; Thaler \& Messmer, 1996). McClintock further viewed cells as being 'smart' not least 
because of their ability to sense internal and external cues, evaluate them, and respond with actions appropriate for survival and morphogenesis. Genes and genomes behave as parallel processing systems in a variety of ways for which a number of models have been described. Not only this, a number of events at the molecular level, such as the formation of transcription complexes, are also parallel in nature. Viewed as a whole we can envisage hierarchies or nestings of parallel systems (e.g., Paton, 1993). Table 3 presents an older and a more contemporary view of genomes (based on Shapiro, 1991) with a clear shift towards a more 'cognitive' perspective.

Table 3. Two Views of the Genome (adapted from Shapiro, 1991)

\begin{tabular}{|l|l|}
\hline \multicolumn{1}{|c|}{ Older view } & \multicolumn{1}{c|}{ Contemporary view } \\
\hline Constant genome & Fluid genome \\
\hline Rigid storage & Dynamic storage \\
\hline $\begin{array}{l}\text { Occasional copying errors and physico-chemical } \\
\text { accidents }\end{array}$ & $\begin{array}{l}\text { Monitoring, correcting and change by dedicated } \\
\text { biochemical complexes }\end{array}$ \\
\hline Bag of individual isolated genes & Multigenic systems \\
\hline $\begin{array}{l}\text { Information utilization in automatic/mechanical } \\
\text { fashion }\end{array}$ & $\begin{array}{l}\text { Integrated, coordinated and complex information } \\
\text { system }\end{array}$ \\
\hline Mechanical-chemical & Information-rich ['smart'] \\
\hline
\end{tabular}

The genome can not only be viewed as a source of code information it is also a structure whose properties, interactions and functions can be modulated by base composition. The DNA sequence can influence the phenotype in more ways than merely encoding a protein product and the notion of nucleotype refers to those conditions of the nuclear DNA which affect the phenotype independently of its encoded (sequence) content. In trying to articulate this idea it becomes important to shift away from the usual ID or sometimes 2D representation of genomes on paper to a 3D perspective in vivo (e.g., Bennett, 1987). A number of functional roles for introns have been suggested including the regulation of gene expression at translational and transcriptional levels, attachment to proteins, chromatin organising role and biophysical effects on the nuclear microenvironment.

So far, we have looked at some cognitive dimensions to hereditary information but there is also a textual influence especially in relation to syntactic issues concerned with code, program, data, translation, transcription and so forth (for a more detailed discussion see Keller, 1995; Paton, 1998). The role played by the text metaphor in the articulation of the nature of hereditary information is summarised by Konopka (1994) who notes that: 
The psychological consequence of this text metaphor was a presupposition that DNA can be a carrier of messages as a text usually is.

Konopka (1994) p. 121

Certain limitations of the text metaphor may be described. Firstly, if the genome were a 'text' it would be an encoded text. Regions of 'text' corresponding to different biological functions could correspond to different 'languages'; they might also be encoded according to different principles so that the cryptosystems as well as the languages would differ. The genome is not static during a cell's lifetime but may be subject to unequal crossover, regional conversion, transposition, retrotransposition and integration of viral DNA. Multiple functions may be related to the same DNA sequence. Thus, as it can be read in more than one way, the text is subtly complex and context-dependent.

The multiple readings of the DNA text have been investigated in detail by a number of authors. For example, Trifonov (e.g., 1989, 1996) has argued that many different combinations of nucleotide sequences carry genetic information, not just the triplet code. Exons can carry several overlapping codes including protein coding, translation framing and in eukaryotes chromatin coding. Trifonov comments that these genetic sequences appear as texts designed for different reading devices, each one seeing in it a message of its own kind. For example, a repetition of some dinucleotides every three steps or multiples thereof in both the prokaryote and eukaryote sequences has been detected. This may be explained in terms of a translation framing code that during mRNA translation with frameshift mutations the ribosome occasionally slips by skipping one base or by adding an extra base to the three base step. The simple periodic pattern hidden within the protein coding sequences helps correct the reading frame. The DNA shape code is expressed in the form of a set of 26 angular parameters that characterise the geometries of possible DNA base pair stacks. Sequence-dependent local shape is a crucial component of proteinDNA recognition and interaction.

The nature and status of the notion of information in biology remains somewhat problematic. Although intuitions tend to suggest that there is more to the biology of information than the syntactic descriptions of classical or algorithmic information theory it is not always clear how the semantic or interpretative (hermeneutic) dimension may be expressed. The work of Varela and Maturana, their development of the notion of autopoiesis and Varela's subsequent ideas regarding enactment should be mentioned at this point as also Kampis' idea of a 'component system'. In terms of the present analysis, it could be argued that Maturana and Varela have accessed the cognitive system metaphor in relation to the notion of an autonomous self-making (autopoietic) device. An autonomous device is defined as having internal self-organising processes, emergent behaviours and organisational closure. This contrasts with machine 
thinking related control and the transformation of inputs to outputs that Varela describes as heteronomous devices (Varela, 1979). The organisational closure property is important in that it helps to set a view on a system that de-emphasises the role or need for an external observer (i.e., an exosystem view). A fuller discussion of exo-/endo- system approaches is beyond the scope of the present paper.

As the present discussion draws towards the verb-glue-text metaphor (next section) let us note that there is a complementarity relation between a measuring (or interpreting) device and what is being measured. A well-known case of such complementarity is the relation between the detecting apparatus and quantum particles in wave/particle duality experiments. Harre (1988) applied the Gibsonian idea of an affordance to help clarify the relationship between measuring apparatus and quantum events. The notion of an affordance is ecological in the sense of interaction and context namely, that they are dispositions of physical things relativised to that with which they interact. The energy flux detected by a piece of apparatus is shaped or formed by that apparatus. Particles can exist nowhere else but in relation to particle-forming apparatus. Apparatus and object exist as a reciprocal pair*. There is also a complementarity on the one had between machine thinking and its interpretative devices and on the other, between text thinking and its interpretative devices. Pattee (1977) argued for a distinction between dynamic and linguistic modes of biosystem description. We currently need at least both of these interpretative modalities to manage our thinking about biosystems.

\section{The Verb-Glue-Text Metaphor}

The last section considered some ways biosystems generate information and emphasised a cognitive viewpoint. A further metaphorical source that can help to clarify the complex of interactions between autonomous processes or within anticipatory and adaptive systems is the emphasis of one dimension of the text metaphor concerned with verbs and relations. This will now be discussed in relation to biomolecular systems although it could also be applied to physiology and ecology.

Several different types of protein molecule exhibit sophisticated information processing capacities and has strengthened a computational view of the cell (for review see Bray, 1995). Enzymes display pattern recognition, memory capacity, context-sensitive activity, handling of fuzzy internal and external events, switch- 
like behaviour (in which the switch can be more subtle than an on-off device), integration of a number of metabolic pathways and other processes, individuality, communication, counting effects and signal amplification. Putting these features together they are more than catalysts and could be described as smart thermodynamic machines. It has been argued elsewhere (e.g., Paton \& Matsuno, 1998) by using text ideas it is possible to think of enzymes as playing the central role of verbs in the cellular metabolic and information processing system. A number of parallels may be made. Like verbs, enzymes can be said to have cases (in the sense elaborated by Fillmore, 1968). Enzyme cases would include substrate, product, regulator(s), location, co-agent(s) and target site(s).

Several other verb-like properties may be described for enzymes and we shall briefly examine context-sensitivity, mood and voice in relation to some glycolytic enzymes. A number of glycolytic enzymes are sensitive to the microenvironments and cell types in which they are found. For example hexokinases, which catalyse the phosphorylation of hexose sugars, come in various isoforms including brain hexokinase (BHK) and gluckinase (liver). Certain metabolic conditions can affect BHK behaviour and there can be rapid and reversible changes between soluble and particulate forms in which the latter is more active than the former. Another example of glycolytic enzyme context-sensitivity is phosphofructokinase-1 (PFK-1) which catalyses the phosphorylation of fructose 6 phosphate (F6P) to fructose 1,6 Bisphosphate (FL6BP). PFK-1 exhibits sigmoidal kinetics when in free solution but a normal saturation curve when membrane-bound (Uyeda, 1992).

The idea that certain enzymes exhibit the mood- or voice-like properties of verbs can be related to their context-sensitivity and also to their internal configuration and localised interactions. In many ways we are dealing with the enzyme's "autecology". In the case of mood the likelihood of an enzyme operating turns from 'can' to 'could', 'will' to 'would' and so forth. This notion of modality in enzyme action is implicit in a number of recent descriptions including: the fluctuating enzyme (e.g., Welch \& Kell, 1986); the seedgermination model (Conrad, 1992) and enzymes as logical agent/verb (Paton et al, 1996; Paton \& Matsuno, 1998). A special case of a context-sensitive enzyme that has "voices" is 6-Phospho-Fructo-2-Kinase/Fructose-2,6-BisPhosphatase (6PF2K/F2,6BP). This enzyme catalyses two opposing reactions:

$$
\begin{aligned}
& \mathrm{F} 6 \mathrm{P}+\mathrm{ATP}->\mathrm{F} 2.6 \mathrm{BP}+\mathrm{ADP} \\
& \mathrm{F} 2,6 \mathrm{BP} \text {-> F6P + ATP }
\end{aligned}
$$

As Pilkis et al (1995) note, 6PF2K/F2,6BP has, in addition to a catalytic role, a key function in intracellular signalling. Here is one case (among many) of when enzymes are far less frequent than the substrates on which they act. Like verbs, they are far less frequent than nouns. 
The relation between networking and complex information processing capacities has already been noted regarding contemporary views of genomes. Intercellular signalling systems employ inter-communicating networks of kinases and phosphatases. These enzymes are often multi-functional and consequently highly integrative. Consider calmodulin-dependent protein kinase II (CaM Kinase II), a large multimeric and multifunctional enzyme that is derived from four genes. It acts on upwards of 49 substrates and is very common. Four functional domains (cases) are defined: catalytic, regulatory (includes inhibitory and CaM binding regions), association (with other subunits) and variable (for targeting and localisation). Apart from the variable domain, the other three domains are highly conserved. CaM Kinase II exhibits a memory capacity as well a being able to amplify signals (discussed further in Paton et al, 1996).

Articulating the relationships between objects and relations or processes between them is complex and also quite subtle. For example, it may presuppose a fixed position or view of a hierarchy or network when as we have seen, biological examples may include a number of levels or scales in time and space. In order to illustrate this; consider the apparently simple 6-node (vertex), 7-arc (edge) network in Figure 3. Many changes in view of this structure could be applied and a small selection is now considered to illustrate some key points. Step A presents the process of abstracting all objects or all relations from the network to produce a set of objects or a set of relations. It is also possible to identify intermediates to this for example, producing the set of all object-relation- object tuples or the set of all nodes with their associated arcs. Step F in Figure 3 summarises a small number of such possibilities. Step B presents the process of abstracting a subgraph or clique of nodes in the network to produce (for example) a compartment. Step D depicts this abstraction as a compartmental model and Step E as a hierarchical tree of objects. Given certain rules it is also possible to step between the compartmental model and the tree. Step $\mathrm{C}$ presents the production of a new network in which the relations of the original network become nodes and the relations in the new network are implied as relations between relations in the original. Hence, process becomes object in this scheme ${ }^{2}$. Technically this representation is called a line graph $h^{3}$. Relations are the adhesive of the network and relations between relations relate to combinational and coherent properties.

Albrecht-Buehler (1990) applied textual ideas to discuss cellular information as being the "glue" that holds the cell together also arguing that the more a cell is decomposed into molecular letters the more its meaning is destroyed. This kind of view is also endorsed by Beloussov who states:

2 Thanks to Ronnie Brown for his comments on this.

3 Thanks to Alan Gibbons for introducing me to this term. 
...instead of splitting a system into as small units as possible, our main task would be to understand its own internal 'language', as well as that of the associated "contexts".

Beloussov (1998), p. 223

Some features of enzyme contexts have been described in terms of analogous verbal processes that are the integrative verbal glue that coheres networks. In order to explore the analogy of 'gluing' we will now look at proteins that are involved in gene expression namely, transcription factors. As a focus we will look at CBP/p. 300.
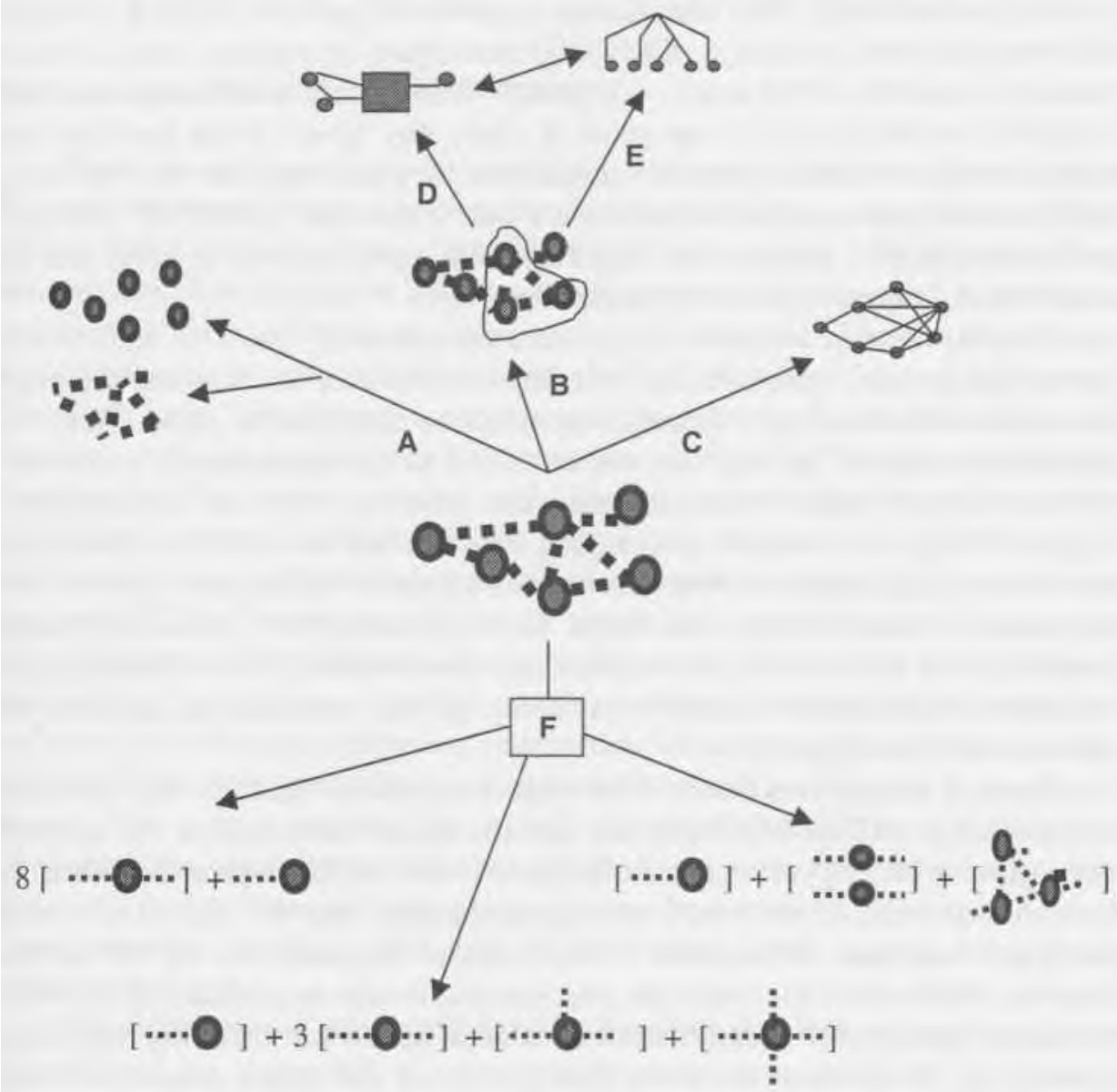

Figure 3. Various 'Gluings'/'Degluings' on a Network (for discussion see text) 
Giles Peters \& Breuning (1998) reviewed the importance of these two multifunctional proteins in some detail. CBP and p300 are large proteins each containing 2441 amino acids. They are the focal points of multiple protein-protein interactions and are coactivator proteins for numerous other transcription factors including CREB, nuclear receptors, signal transducer and activator of transcription (STAT) proteins, p53, and the basal transcription proteins. Members of the CREB grouping bind to cAMP response elements (CREs) in the promoters of the genes they induce which include somatostatin, enkephalin and a-gonadotrophin. It is possible to say that they act like 'glue' in a number of ways related to molecule- molecule bindings and interactions, enzymatic processes, as a physical bridge between various transcription factors and the basal transcriptional machinery, acting as histone acetyltransferases (HATs) and so linking transcription to chromatin remodelling. They also mediate negative and positive crosstalk between different signalling pathways. $\mathrm{CBP} / \mathrm{p} 300$ participate in various basic cellular functions, including DNA repair, cell growth, differentiation and apoptosis. It is important to note that from our point of view, this "glue" is not just that the molecules have intrinsic adhesive properties, they also provide the cell with combinatorial and cohesive properties at a functional level. p300/CBP is a very good example of a protein fulfilling functorial roles both as a verb and as a connector in the cellular informational economy.

We may use this example to articulate the nature of 'glue' as both object (noun) and process (verb). Firstly, it is important to keep in mind the previous discussion related to Figure 3, that process can be described as object. Next we define three types of 'gluing' that can be related to the emergence of coherence within a network: adhesion, combination and cohesion. 'Network' as used here is not referring to a static or unchanging structure not least because processes can have varying lengths of time associated with them. Adhesion is local to two interacting components at a particular level of description. Adhereing parts become joined and several joined adhesions can combine. When combinations combine a coherent object can emerge. These 'gluing' processes are reversals of steps A and F in Figure 3.

Figure 4 summarises some of the relations between 'gluings' and function with respect to $\mathrm{CBP} / \mathrm{p} 300$. Object and process can be subsumed as one general term 'glue' with respect to the multi-functionality of these proteins. What is more, it is possible to introduce topological thinking into the context in which the 'glue' functions. This relates to the terms in the boxes on the left of the diagram. Multi-enzyme complexes and supramolecular assemblies of protein- protein and protein-DNA could also be included in this scheme. This returns us to some of the discussions in the first section of this paper concerned with conceptual issues. Tools of thought for dealing with multi-functionality, nestings and multiple hierarchies of relations are poorly-defined and often ill-considered. 
The verb-glue-text metaphor can help contain object and process within a single coherent conceptual framework.

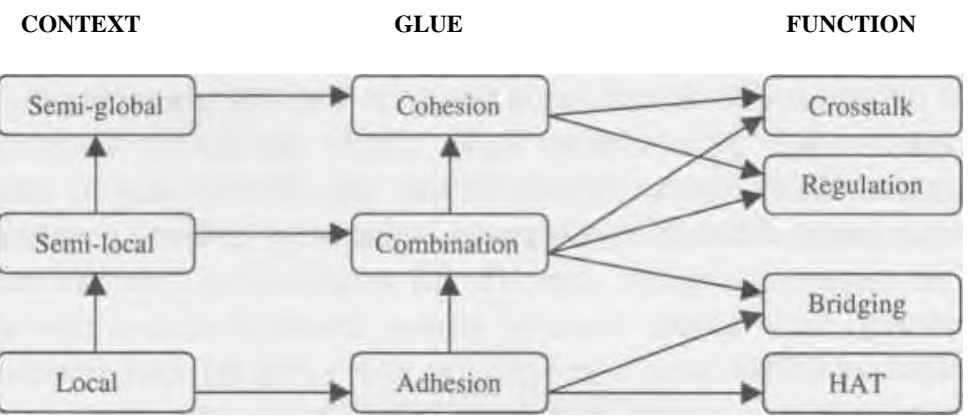

Figure 4. Some 'Gluings’ Associated with CBP/p300

There are other examples of 'gluing' across hierarchical levels. For example, Conrad's notion of vertical information flow in hierarchies (e.g., Conrad, 1989) can be said to act as a 'glue'. In this proposal macroscopic information such as sensory signals impinging on a cell are transduced into microscopic (i.e., quantum) information via intracellular signalling systems. In turn, the microscopic processes are transduced in macroscopic actions via the intracellular signalling system. The traditional hierarchical molecule-cell-organism is de-emphasised in this scheme, as levels of scale are less important than the information processing. Information flow acts as a 'glue' within and between organisational levels. In a different context, Jabłonka (1994) argues that the emergence of levels of individuality beyond unicellular organisation depends on epigenetic inheritance systems (EISs). This helps explain the origin and maintenance of division of labour between cell types in multicellular organisms. EISs allow the inheritance not only of instructions but also of their functional states. These states can influence how the instructions are interpreted. Jabłonka argues that this capacity to inherit more than instructions will support the cohesion of higher organisational levels. She proposes that EISs would allow groups of cells to emerge as phenotypically distinct types because acquired epigenetic patterns would persist and could lead to cohesive homogeous colonies. Interactions between (not within) these cohesive wholes would give rise to multicellular systems comprising different cell types.

The development and application of the verb-glue-text metaphor may be constrained by a number of conceptual issues concerned with combining interrelated parts and then assigning a single collective term. This can be seen when a contrast is made between the occurrence and internal structure of class 
concepts and collection concepts. Collective nouns (e.g., family, army) are relatively rare when compared with class terms. Classes produce is_a or $i s_{-} p a r t \_o f$ hierarchies and use few verb types. Collections may produce hierarchies or networks and many verb types may be used; they require relationships between parts (Markman et al, 1980). Psychological studies have indicated that relational structures of events and themes are a common ways of organising information/ knowledge but we do not often have single words for them (Markman \& Hutchinson, 1984; Paton, 1993b). People may find it easy to collect terms together but more difficult to assign an organising collecting concept. Some collective nouns are quite specific in application (unless when used metaphorically) for example, brace of grouse, brood of hens or cete of badgers. Other collective nouns have a general use and a rich internal structure. Rather than digressing into a study of collective nouns in common usage we shall look at a small selection of biological examples (see Table 4).

Table 4. Some Collective Nouns and their Internal Organisation

\begin{tabular}{|c|c|c|}
\hline Collective Noun & Brief description & Internal Organisation \\
\hline Operon & $\begin{array}{l}\text { A controllable unit of transcription consisting of a } \\
\text { number of structural genes transcribed together and at } \\
\text { least two distinct regions: operator and promoter. }\end{array}$ & $\begin{array}{l}1 \text { dimensional array of } \\
\text { interactions }\end{array}$ \\
\hline Regulon & $\begin{array}{l}\text { A group of genes or operons that are regulated together } \\
\text { but may be located a good distance from each other in } \\
\text { the genome. }\end{array}$ & Network of interactions \\
\hline Metabolon & $\begin{array}{l}\text { A highly organized supramolecular complex of } \\
\text { enzymes involved in catalyzing certain sequential } \\
\text { reactions. }\end{array}$ & f Network of interactions \\
\hline Genome & $\begin{array}{l}\text { All the genetic material in the chromosomes of a } \\
\text { particular organism. }\end{array}$ & $\begin{array}{l}\text { Bag that is becoming very } \\
\text { organised. }\end{array}$ \\
\hline Transcriptome & The set of genes expressed from a genome. & Bag or set \\
\hline Biome & $\begin{array}{l}\text { A large, distinct, interacting and complex biotic } \\
\text { community and its environment. }\end{array}$ & Spa \\
\hline
\end{tabular}

Table 4 considers six biological collective nouns and provides a brief description together with a comment on the internal organisation of the collection. Even a gene is a highly structured system in which the bases which make up the exons (coding regions) and introns are dispersed in a non random manner. The cytoplasm of a cell was conceived as a bag of chemicals although it is becoming much clearer that it is a highly organised structure. Similarly the genome may be conceived as a bag or set of genes although as already discussed above the 
contemporary view is of a fluid genome that operates as an integrated, coordinated and complex information system. The shift is from set to collection, from bag to integrated structure. These collecting terms provide a level of integration that relates both structure and functionality. Clearly the proliferation of such terms means that the vocabulary and also the potential for misunderstanding as knowledge increases is a problem when the specialisation of the subject continues apace. Some collection terms refer to physical structures whilst others may be less physical, more functional. The challenge is to contain the diversity of terms within a common cohesive conceptual framework. The verb-gluetext metaphor can facilitate this.

\section{Concluding Remarks}

The discussion has ranged quite broadly across many domains and presented a set of tools of thought that can provide a cohesive framework for integrating diverse biological knowledge. This general framework has also been applied to pervasive system-related ideas such as hierarchy, network and organisation. Three important and related metaphorical constructs have been explored: the ecology of information, the cognitive system and the verb-glue-text metaphor. Much more could be written not only about systemic metaphors but also others for example in relation space. However, it is hoped that the reader will now have a richer appreciation of the conceptual complexity of biosystems thinking as well as an awareness of some of the ways the subject could evolve as knowledge continues to increase and the need for integration becomes ever more pressing.

\section{Acknowledgements}

I am grateful to a number of people for their comments related to various ideas developed in this paper including, Lev Beloussov, Ronnie Brown, John Easterby, Andree Ehresmann, Michael Fisher, Alan Gibbons, Rachel Giles, Rom Harre, Koichiro Matsuno, Mary Meyer, Howard Parish and Rick Welch.

\section{References}

Albrecht-Buehler, G. (1990), "In Defense of Nonmolecular Biology", International Review of Cytology, 120, 191-241.

Albrecht-Beuhler, G. (1998) CELL INTELLIGENCE Website

http://www.basic.nwu.edu/g-buehler/cellint.htm 
Arhem, P. (1996), "Vertical Information Flow in the Brain: on Neuronal Micro Events and Consciousness", BioSystems, 38, 2/3, 191-198.

Conrad M (1990), "Quantum mechanics and cellular information processing: the selfassembly paradigm", Biomed Biochim Acta, 49, 8-9, 743-55.

Conrad, M. (1992), “The Seed Germination Model of Enzyme Catalysis”, BioSystems, 27, 223 233.

Beloussov, L. V. (1998), The Dynamic Architecture of a Developing Organism, Kluwer. Bennett, M. D., 1987, "Variation in Genomic Form in Plants and its Ecological Implications", New Phytol. 106 (Suppl.), 177-200.

Bertalanffy, L. von (1973) General System Theory, Harmondsworth: Penguin.

Bray, D. (1995), "Protein Molecules as Computational Elements in Living Cells", Nature, 376, 307-312.

Emmeche, C. \& Hoffmeyer, J. (1991), "From Language to Nature: The Semiotic Metaphor in Biology", Semiotica, 84(1/2), 1-42.

Erdi, P. (1996), “The Brain as a Hermeneutic Device”, Biosystems. 1996;38(2-3): 179-89.

Fillmore, C. J. (1968), "The Case for Case", in Bach, E. \& Harms, R.T. (eds), Universals in Linguistic Theory, New York: Holt, Rinehart \& Winston, 1-88.

Fisher, M., Paton, R. C. \& Matsuno, K. (in press), “Intracellular Signalling Proteins as 'Smart' Agents in Parallel Distributed Processes", to appear in BioSystems.

Forbes, S. A. (1887), "The Lake as a Microcosm”, Bull. Peoria Sci. Assoc., Illinois Nat. Hist. Surv. Bull., 15, 537-550.

Getting, P. A. (1989), "Emerging Principles Governing the Behaviour Operation of Neural Networks", Аnnu. Rev. Neuroscience, 112, 185-204.

Giles, R. H., Peters, D. J. M. \& Breuning, M. H. (1998), “Conjunction dysfunction: CBP/p300 in human disease", Trends in Genetics, 14, 5, 178-183.

Golley, F. B. (1993), A History of the Ecosystem Concept in Ecology, Yale University Press: New Haven.

Harre, R. (1986), Varieties of Realism: a Rationale for the Natural Sciences, Blackwell, Oxford.

Harre, R., (1988), "Parsing the Amplitudes", in Brown, H.R. \& Harre, R. (eds), Philosophical Foundations of Quantum Field Theory, Oxford: Clarendon Press pp59-71.

Holmquist, G. P. \& Filipsk, J. (1994), "Organisation of Mutations along the Genome: a Prime Determinant of Genome Evolution", Trends in Ecology and Evolution, 9, 2, 65-69.

Hutchinson, G. E. (1948), "Circular Causal Systems in Ecology", Ann. N.Y. Acad. Sci., 50, 221246.

Hutchinson, G. E. (1965), The Ecological Theatre and the Evolutionary Play, Yale University Press.

Jabłonka, E. (1994), "Inheritance Systems and the Evolution of New Levels of Individuality", J. theor. Biol., 170, 301-309.

Kampis, G. (1994), "Biological Evolution as a Process Viewed Internally”, in Atmanspacher, H. \& Dalenoort, G. (eds), Inside versus Outside, Synergetics Series 63, Berlin: Springer Verlag, 85-110. 
Keller, E. F. (1995), Refiguring Life: Metaphors of Twentieth Century Biology, N.Y.: Columbia University Press.

Konopka, A. K. (1994), "Fundamentals of Biomolecular Cryptology", in Smith, D.W. (ed), Biocomputing Informatics and Genome Projects, London, San Diego: Academic Press, 119-174.

Mansson, B. A., \& McGlade, J. M. (1993), "Ecology, Thermodynamics and Odum's Conjectures", Oecologia, 93:582-596

Marijuan, P. C. (1996), 'Gloom in the Society of Enzymes': on the Nature of Biological Information, BioSystems, 38, 2/3, 163-171.

Markman, E. M., Elorton, M. S. \& McLanahan, A. G. (1980), "Classes and Collections: Principles of Organisation in the Learning of Hierarchical Relations", Cognition, 8, 227241.

Markman, E. M. \& Hutchinson, J. E. (1984), “Children's Understanding of Constraints of Word Meaning: Taxonomic Versus Thematic Relations", Cognitive Psychology, 16, 1-27. Mirowski, P. (1993), "Ecology in the Mirror of Economics", History of Economics Society, Monthly Guest Editorial for HES, and available from URL:

http://cpmserv.cpm.ehime-u.ac.jp/ehnet/HisEcSoc/Resources/Editorials/Mirowski/ leditorial.shtml

Paton, R. C. (1992), “Towards a Metaphorical Biology”, Biology and Philosophy, 7, 279-294. Paton, R. C. (1993a), "Some Computational Models at the Cellular Level”, BioSystems, 29, 6375.

Paton, R. C. (1993b), “Understanding Biosystem Organisation I: Verbal Relations”, International Journal of Science Education., 15, 4, 395-410.

Paton, R. C. (1997), "Glue, Verb and Text Metaphors in Biology", Acta Biotheoretica, 45, 115.

Paton, R. C. (1998), "The Ecologies of Hereditary Information", Cybernetics and Human Knowing, 5, 4, 31-44.

Paton, R., Staniford, G. \& Kendall, G. (1996), "Specifying Logical Agents in Cellular Hierarchies", in Cuthbertson, R., Holcombe, M. \& Paton, R. (eds), Computation in Cellular and Molecular Biological Systems, World Scientific: Singapore, 105-119

Paton, R. C. \& Matsuno, K. (1998), "Some Common Themes for Enzymes and Verbs", Acta Biotheoretica, 46, 131-140.

Pattee, H. H. (1977), "Dynamic and Linguistic Modes of Complex Systems", International Journal of General Systems, 3, 259-266.

Pilkis, S. J., Claus, T. H., Kurland, I. J. \& Lange, A. J. 1995, "6-Phosphofructo-2-kinase/ Fructose-2,6-Bisphosphatase: A metabolic signalling enzyme”, Annu. Rev. Biochem., 64: 799-835.

Richmond, M. H. (1979), “'Cells' and 'Organisms' as Habitats for DNA”, Proceedings of the Royal Society of London B. 204, 235-250.

Roche, J. (1990), "New Tasks for the Philosophy of Physics", in Bhaskar, R. (ed) Harre and His Critics, Oxford: Blackwell, pp. 89-111.

Rosen, R. (1985), Anticipatory Systems, Oxford: Pergamon Press. 
Rosen, R. (1991), Life Itself Columbia University Press: New York.

Sattler, R. (1986), Biophilosophy, Springer: Berlin.

Schiller, J. (1968), "Physiology's Struggle for Independence in the First Half of the 19th Century", History of Science, 7, 64-89.

Shapiro, J. A. (1991), "Genomes as Smart Systems", Genetica, 84, 3-4.

Shapiro, J. A. (1992), "Barbara McClintock, 1902-1992", BioEssays 14, 791-792. Shapiro, J.

A. (1997), "Genome Organization, Natural Genetic Engineering and Adaptive

Mutation", Trends in Genetics, 13, 3, 98-104.

Shepherd, G. M. (1990), "The Significance of Real Neural Architectures for Neural Network

Simulations", in E.L. Schwartz (ed), Computational Neuroscience, Cambridge MA: MIT, 82-96.

Thaler, D. S. (1994), "The Evolution of Genetic Intelligence”, Science, 264, 224-225.

Thaler, D. S. \& Messmer, B. T. (1996), "Evolution of Genetic Intelligence”, in Meyers,

R. A. (ed), Encyclopedia of Molecular Biology and Molecular Medicine Volume 2, Weinheim: VCH, 407-414.

Tansley, A.G. (1935), "The Use and Abuse of Vegetational Concepts and Terms", Ecology, 16, 3, 284-307.

Taylor, P. J. (1988), "Technochratic Optimism, H. T. Odum, and the Partial Transformation of Ecological Metaphor after World War II", Journal of History of Biol., 21, 2, 213-244.

Trifonov, E. N. (1989), “The Multiple Codes of Nucleotide Sequences”, Bull. Math. Biol., 51, 4, 417-432.

Trifonov, E. N. (1996), "Interfering Contexts of Regulatory Sequence Elements", CABIOS, 12, $5,423-429$.

Uyeda, K. (1992), "Interactions of Glycolytic Enzymes with Cell Membrane”, Curr.Topics in Cell Regulation, 33, 31-46.

Varela, F. J. (1979), Principles of Biological Autonomy, New York: North Holland. Welch, G. R. (1987), "The Living Cell as an Ecosystem: Hierarchical Analogy and Symmetry", Trends in Ecology and Evolution, 2, 10, 305-309.

Welch, G. R. \& Keleti, T. (1987), "Is Cell Metabolism Controlled by a Molecular Democracy or by a Supramolecular Socialism?", Trends in Biochemical Sciences., 12, 216-217.

Welch, G. R. \& Kell, D. B. (1986), Not just Catalysts - Molecular Machines in Bioenergetics, in Welch, G.R. (ed), The Fluctuating Enzyme, New York: John Wiley, 451-492. 